\title{
High T-cell immune activation and immune exhaustion among individuals with suboptimal CD4 recovery after 4 years of antiretroviral therapy in an African cohort
}

Damalie Nakanjako ${ }^{1,2^{*}}$, Isaac Ssewanyana ${ }^{3}$, Harriet Mayanja-Kizza' ${ }^{1}$, Agnes Kiragga², Robert Colebunders 5,6, Yukari C Manabe ${ }^{2}$, Rose Nabatanzi ${ }^{3}$, Moses R Kamya ${ }^{1}$, Huyen Cao ${ }^{4}$

\begin{abstract}
Background: Antiretroviral therapy (ART) partially corrects immune dysfunction associated with HIV infection. The levels of T-cell immune activation and exhaustion after long-term, suppressive ART and their correlation with CD4 T-cell count reconstitution among ART-treated patients in African cohorts have not been extensively evaluated.

Methods: T-cell activation (CD38+HLA-DR+) and immune exhaustion (PD-1+) were measured in a prospective cohort of patients initiated on ART; 128 patient samples were evaluated and subcategorized by CD4 reconstitution after long-term suppressive treatment: Suboptimal [median CD4 count increase 129 (-43-199) cells/ $\mu l], N=34]$, optimal [282 (200-415) cells/ $\mu \mathrm{l}, \mathrm{N}=64$ ] and super-optimal [528 (416-878) cells/ $\mu \mathrm{l}, \mathrm{N}=30$ ].

Results: Both CD4+ and CD8 T-cell activation was significantly higher among suboptimal CD4 T-cell responders compared to super-optimal responders. In a multivariate model, CD4+CD38+HLADR+ T-cells were associated with suboptimal CD4 reconstitution [AOR, 5.7 (95\% Cl, 1.4-23, $P=0.014)]$. T-cell exhaustion (CD4+PD1+ and CD8+PD1+) was higher among suboptimal relative to optimal $(P<0.001)$ and super-optimal responders $(P<0.001)$. T-cell exhaustion was significantly associated with suboptimal responders [AOR, $1.5(95 \% \mathrm{Cl}, 1.1-2.1), P=0.022]$.

Conclusion: T-cell activation and exhaustion persist among HIV-infected patients despite long-term, sustained HIV-RNA viral suppression. These immune abnormalities were associated with suboptimal CD4 reconstitution and their regulation may modify immune recovery among suboptimal responders to ART.
\end{abstract}

\section{Background}

Although antiretroviral therapy (ART) partially corrects immune dysfunction associated with HIV infection, abnormalities of immune activation markers persist in many patients [1-3]. ART reduces the levels of T-cell activation by mechanisms independent of viral load [1-3]. Nevertheless, immune activation (as measured by expression of HLA-DR and CD38 on monocytes and $\mathrm{T}$-cells) remained significantly higher among HIVinfected patients relative to the HIV-negative controls one year after viral suppression [4].

\footnotetext{
* Correspondence: drdamalie@yahoo.com

'Department of Medicine, Makerere University School of Medicine, Kampala, Uganda

Full list of author information is available at the end of the article
}

Up to $40 \%$ of individuals receiving ART have suboptimal CD4 T-cell recovery despite sustained HIV-RNA viral suppression [5-7]. HIV-RNA viremia and T-cell immune activation have been previously shown to be strong predictors of HIV disease progression [8]. In contrast, there is conflicting data on the influence of T-cell activation on CD4 T-cell recovery among patients on successful ART $[9,10]$. Furthermore, there is limited data on the influence of immune activation on CD4 count and functional recovery with sustained HIV-RNA suppression in African populations $[11,12]$, where endemic co-infections may dampen the immune response [13].

Increased $\mathrm{T}$-cell apoptosis has been proposed as a mechanism for unsatisfactory immune recovery [7]. PD-1 expression is increased during HIV-1 infection [14] and

\section{Biomed Central}


negatively regulates $\mathrm{T}$-cell activity and can be measured by $\mathrm{T}$-cell expression of Programmed Death-1 (PD-1) marker, an inducible molecule that is expressed on all lymphoid cells that are highly susceptible to apoptosis $[15,16]$. This study reports the levels of $\mathrm{T}$-cell immune activation and $\mathrm{T}$-cell exhaustion among adult Ugandans with sustained HIV-RNA viral suppression after 4 years of ART.

\section{Methods}

\section{Study setting and participants}

Between April, 2004 and April, 2005, 559 consecutive ART-naïve HIV-infected patients, were initiated on ART and enrolled into the Infectious Diseases Institute (IDI) prospective observational research cohort as previously described [17]. Patients were initiated on first-line ART at CD4 counts $\leq 200$ cells $/ \mu$ l according to Ugandan guidelines for ART initiation at the time. Drugs were provided through the Global Fund (a generic combined formulation of stavudine [d4T, lamivudine [3TC], and nevirapine [NVP] and the US President's Emergency Plan for AIDS Relief (a combined formulation of zidovudine [ZDV] and 3TC plus efavirenz [EFZ] or nevirapine [NVP]. Patients with toxicity to ZDV were changed to tenofovir [TDF]. All patients received cotrimoxazole (or dapsone) prophylaxis according to the national policy to provide cotrimoxazole to all people living with HIV (PLHIV). Adherence to ART was encouraged by at least 3 individual and group counseling sessions. Patients were reviewed monthly by the study physicians that evaluated among others; adherence to medication, toxicities and acute infections. HIV RNA viral loads, complete blood counts and CD4 lymphocyte counts were measured 6 monthly intervals.

After 4 years of follow up on ART, 252/559 (45\%) patients had sustained HIV-RNA viral suppression. Of these, 41 were excluded due to the following reasons; death $(n=25)$, lost to follow-up $(n=5)$, voluntary request to transfer to and voluntary termination from the study $(\mathrm{n}=11)$. We excluded patients that had an opportunistic infection in the previous 6 months. Up to 128 patients with chronic HIV infection successfully suppressed on ART with HIV RNA levels < 400 copies/ $\mathrm{ml}$ for 4 years were evaluated: 34 patients (cases) with suboptimal CD4 reconstitution, 64 with optimal CD4 reconstitution (controls) and 30 with super-optimal CD4 reconstitution (controls); see Figure 1.

\section{Definition of suboptimal CD4 reconstitution}

Various definitions have been used to describe suboptimal CD4 reconstitution following ART including the magnitude of the CD4 cell increase [18]. Kaufmann et al defined suboptimal CD4 reconstitution an absolute CD4 count $<500$ cells $/ \mu$ after 5 years of sustained viral loads $<1000$ copies [19]. However, less than one-third of all the patients in our African study cohort had attained an absolute CD4 count $\geq 500$ cells $/ \mu$ l. Therefore we used a cohortspecific definition of suboptimal CD4 reconstitution in order to consider the whole spectrum of CD4 recovery. The magnitude of CD4 increase (difference between absolute CD4 counts at baseline and absolute CD4 counts after 4 years of ART), for the 211 patients with sustained HIVRNA viral suppression, was grouped into 4 quartiles. Cases of 'Suboptimal CD4 reconstitution' included patients within the lowest quartile and the controls with 'Optimal CD4 reconstitution' included patients within the two middle quartiles while the controls with 'Super-optimal CD4 reconstitution' included patients within the highest quartile of CD4 increase (see Figure 1). Written informed consent was obtained from all participants. This study was approved by national institutional review board; the Uganda National Council of Science and Technology. The immunology assays were performed at the cytotoxic $\mathrm{T}$ lymphocyte laboratory (CTL) at the Joint clinical research center (JCRC), Kampala, Uganda.

\section{PBMC separation}

Fifty mls of whole blood, collected in ACD-A bottles, was processed for PBMC separation within 4 hours of collection. PBMCs were separated by Ficoll-Hypaque density configuration, washed and re-suspended in phosphate buffer saline (PBS) containing heat inactivated fetal calf serum (FCS). PBMCs were frozen and stored in FBS with $10 \%$ dimethyl sulfoxide (DMSO), in liquid nitrogen until assay time.

\section{Cell surface staining for immune profile}

PBMC were thawed and rested overnight before surface staining. PBMC viability was $90 \%$ and above. Surface staining for immune profile was done in two panels by incubating with the following antibodies; CD3 APC, CD4 PerCP-Cy5.5, HLA-DR FITC and CD38 PE (BD Biosciences San Jose, CA) for immune activation and CD3 FITC, CD4 PerCP-Cy5.5, PD-1 APC and CD127 $\mathrm{PE}$ (BD Biosciences San Jose, CA) for cell function/ exhaustion. The florescence signals were measured by 4-color flow Facscalibur

(BD Biosciences San Jose, CA). In general, at least 50,000 events in the CD3-positive gate were collected. Gating was standardized and set using fluorescence minus one controls (FMOs) for HLADR, CD38 and PD1. Data were analyzed using FLOWJO software (TreeStar, San Carlos, CA). Immune activation was defined as the percent of CD38+ HLA DR+ T-cells. PD-1 level was defined as the percent expression of PD-1 APC $\mathrm{CD}^{+}$ $\mathrm{CD}^{+}$(or CD4+) T-cells, respectively. 


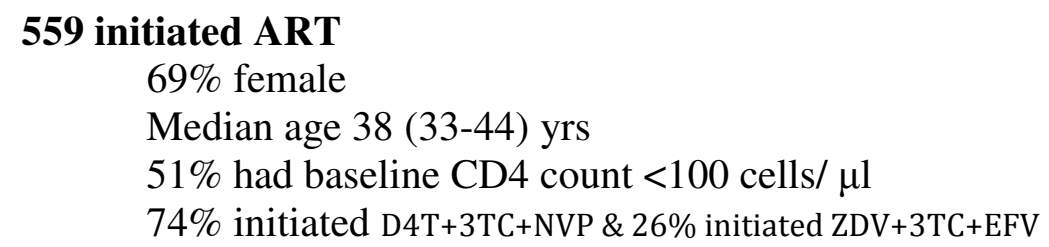

Figure 1 Profile of patients on antiretroviral therapy within the Infectious Disease research cohort.

\section{Co-infections}

All participants were tested for concurrent acute infections that are associated with immune activation. Among other tests, patients were tested for hepatitis B surface antigen (hepatitis B surface antigen version 3, Murex Biotech LTD, Darford, UK) and intestinal helminthes (using stool microscopy for parasites, ova and cysts and modified $\mathrm{ZN}$ stain for cryptosporidia infestations) as well as C-reactive protein levels, a biomarker for acute non-specific acute infection.

\section{Statistical analysis}

We compared percentages of activated (CD38+HLADR+) $\mathrm{T}$-cells between patients with suboptimal, optimal and super-optimal CD4 reconstitution after 4 years of ART with plasma HIV-RNA levels below 400 copies/ml. Chi square and Kruskal-Wallis tests were used for unadjusted comparisons between the three groups for categorical and continuous variables respectively. Wilcoxon rank sum test was used compare immunological and clinical parameters among suboptimal and super-optimal responders. Logistic 
regression was used to determine relationship between $\mathrm{T}$ cell activation and CD4 reconstitution. All factors that were significant predictors of suboptimal CD4 reconstitution in unadjusted analyses $(\mathrm{P}<.10)$ were included in the multivariate model in a stepwise manner.

\section{Results}

\section{Characteristics of participants}

Overall, 128 individuals with sustained HIV-RNA viral loads $<400$ copies/ml after 4 years of ART were evaluated: 34 patients with 'suboptimal CD4 reconstitution', 64 with 'optimal CD4 reconstitution' and 30 with 'super-optimal CD4 reconstitution'. Median CD4 count increase (difference between baseline and 4 years of ART) was 129 (-43-199), 282 (200-415) and 528 (416878 ) cells/ $\mu$ for the suboptimal, optimal and superoptimal respectively (see Figure 1). Baseline clinical characteristics were similar among the three patient categories both at baseline and after 4 years of ART except CD4 counts that were significantly different after 4 years of ART $(P<0.001)$; see Table 1 .

\section{T-cell activation}

$\mathrm{T}$-cell activation was measured by co-expression CD38 and HLADR (CD4+ CD38+HLADR+ and CD8+CD38
+ HLADR+) on the T cell surface (see Figure 2). CD4 and CD8 T-cell activation was significantly higher among 'suboptimal' responders compared with the 'optimal' $(p<0.001)$ and 'super-optimal' responders $(p<$ 0.001); see Figure 3. In addition, CD4+CD38+HLADR+ $\mathrm{T}$-cells were independent predictors of suboptimal CD4 reconstitution [Adjusted odds ratio, AOR, 5.7 (95\% confidence interval, 95\% CI, 1.4-23, $\mathrm{P}=0.014)]$.

\section{T-cell exhaustion}

Immune exhaustion was measured by expression of PD1 on CD4 (CD4+PD1+) and CD8 (CD8+PD1+) T-cells (see Figure 4). PD-1 expression was significantly higher among 'suboptimal responders' compared with the optimal $(p<0.001)$ and 'super-optimal' $(p<0.001)$ responders (see Figure 5). CD4+PD1+ remained significantly higher among suboptimal responders at multivariate analysis [AOR, 1.5 (95\%CI 1.1-2.1), $P=0.022$ ]; see Table 2.

\section{Peripheral blood parameters}

The total white blood cell count and eosinophil percentage were significantly lower among suboptimal responders relative to super-optimal responders; $P$-values; $<0.003$, and 0.012 respectively (see Table 2 ). However, at

Table 1 Characteristics of 128 patients with sustained viral suppression after 4 years of antiretroviral therapy at the Infectious Diseases Institute research cohortT

\begin{tabular}{|c|c|c|c|c|}
\hline & $\begin{array}{l}\text { Sub-optimal CD4 reconstitution } \\
\text { (Cases) } \\
\mathrm{N}=34\end{array}$ & $\begin{array}{l}\text { Optimal CD4 reconstitution } \\
\text { (Controls) } \\
\mathrm{N}=64\end{array}$ & $\begin{array}{l}\text { Super-optimal CD4 reconstitution } \\
\text { (Controls) } \\
\mathrm{N}=30\end{array}$ & P value* \\
\hline \multicolumn{5}{|l|}{ At baseline } \\
\hline Age (yrs) [median (IQR)] & $36(31-42)$ & 33 (30-38) & $35(31-43)$ & 0.509 \\
\hline Female gender [n (\%)] & $21(62)$ & $49(77)$ & $26(87)$ & 0.066 \\
\hline BMI [median (IQR)] & $20(19-23)$ & $20(19-23)$ & $20(19-23)$ & 0.935 \\
\hline CD4 cells/Ml [median (IQR)] & $111(62-151)$ & $105(40-176)$ & $115(97-185)$ & 0.447 \\
\hline < 100 cells/ $\mu \mathrm{l}[\mathrm{n}(\%)]$ & $20(59)$ & $35(55)$ & $15(30)$ & 0.779 \\
\hline \multicolumn{5}{|l|}{ ART regimen } \\
\hline D4T-3TC-NVP/EFZ [n (\%)] & $17(50)$ & $43(67)$ & $22(73)$ & \\
\hline ZDV-3TC-NVP/EFZ [n (\%)] & $17(50)$ & $21(33)$ & $8(27)$ & 0.116 \\
\hline Hemoglobin [ median (IQR)] & $12(11-13)$ & $11(10-13)$ & $11(10-13)$ & 0.473 \\
\hline \multicolumn{5}{|l|}{ After 4 years of ART } \\
\hline CD4 cells/Ml [median (IQR)] & $220(183-248)$ & $407(334-456)$ & $985(438-1290)$ & $<0.001$ \\
\hline$<350$ cells/ $\mu \mathrm{l}[\mathrm{n}(\%)]$ & $34(100)$ & $19(30)$ & $0(0)$ & $<0.001$ \\
\hline BMI [median (IQR)] & $21(19-25)$ & $22(20-24)$ & $22(20-24)$ & 0.062 \\
\hline Hemoglobin [ median (IQR)] & $14(12-15)$ & $13(12-14)$ & $13(12-14)$ & 0.969 \\
\hline Hepatitis B positive [n] & 1 & 5 & 1 & 0.033 \\
\hline \multicolumn{5}{|l|}{ ART regimen } \\
\hline D4T-3TC-NVP/EFZ [n (\%)] & $13(38)$ & $41(64)$ & $17(57)$ & \\
\hline ZDV-3TC-NVP/EFZ [n (\%)] & $21(62)$ & $18(28)$ & $13(43)$ & \\
\hline TDF-3TC-NVP/EFZ [n (\%)] & $0(0)$ & $5(8)$ & $0(0)$ & 0.008 \\
\hline
\end{tabular}

*Chi square test was used for categorical variables and Kruskal-Wallis test was used for the continuous variables.

ПAll patients initiated antiretroviral therapy at CD4 200 cells/ $\mu \mathrm{l}$ and below. The magnitude of CD4 increase from the baseline counts was grouped into 4 quartiles; 'Suboptimal CD4 reconstitution' includes patients that lie in the lowest quartile, 'Optimal CD4 reconstitution' includes a sample of patients that lie in the two middle quartiles and 'Super-optimal CD4 reconstitution' includes patients that lie in the highest quartile of CD4 increase. 


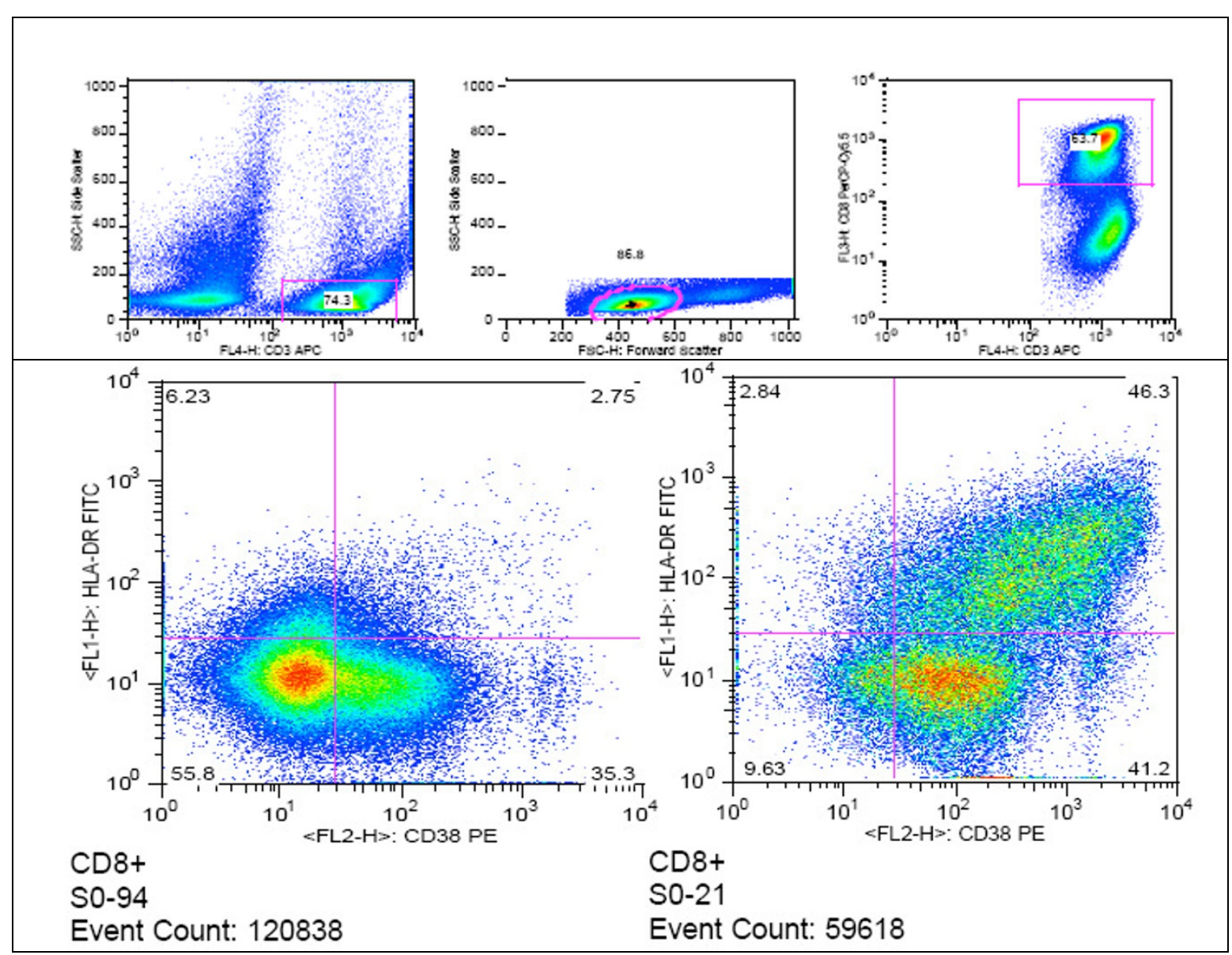

Figure 2 Flow cytometry analysis of CD38+HLADR+ CD8 T cells. The upper panel shows the gating strategy for co-expression of CD38 and HLADR (immune activation) by CD8 T cells. The lower panel shows a 'super responder' with a typically low proportion of activated CD8 T cells (left) and a 'suboptimal responder' with a typically high proportion of activated CD8 T cells.

multivariate analysis these parameters were not significant predictors of suboptimal CD4 reconstitution (data not shown).

\section{Co-infections}

All participants were tested for concurrent acute infections that are associated with immune activation. Of the 128 patients with sustained viral suppression, 7(6\%) were positive for hepatitis B surface antigen, only 13 (10\%) had a C-reactive protein level above $6 \mathrm{mg} / \mathrm{dl}$. No intestinal parasitic infection was observed in all participants using both stool microscopy for ova and parasites and modified ZN stain.

\section{Discussion}

Immune activation, as defined by expression of HLA-DR and CD38 by T-cells typically normalizes several months following successful initiation of ART [20]. However, we describe high levels of immune activation in a cohort of HIV infected Ugandan adults four years following ART; a report that is consistent with several other studies from the Western cohorts $[21,22]$. Contrary to previous studies from the West [10], this study demonstrated that suboptimal CD4 reconstitution is strongly associated elevated $\mathrm{T}$ cell activation, regardless of initial clinical parameters. Various immunosuppressive agents have been investigated in the interest of "turning off" excessive immune activation $[23,24]$ as an intervention to improve patients' responses to ART. Therefore downregulation of immune activation is a potential strategy to optimize immune recovery among ART-treated patients with suboptimal CD4 reconstitution. Noteworthy, the study participants were started on ART at CD4 counts $<250$ cells $/ \mu$ l. This is clearly severe immune suppression considering the growing evidence initiation of ART at higher CD4 counts yields better clinical and immunological outcomes [25,26]. This study adds evidence to the current evidence that early initiation of ART not only increases CD4 counts and survival [6,25-27], but also lowers the levels of T-cell activation 


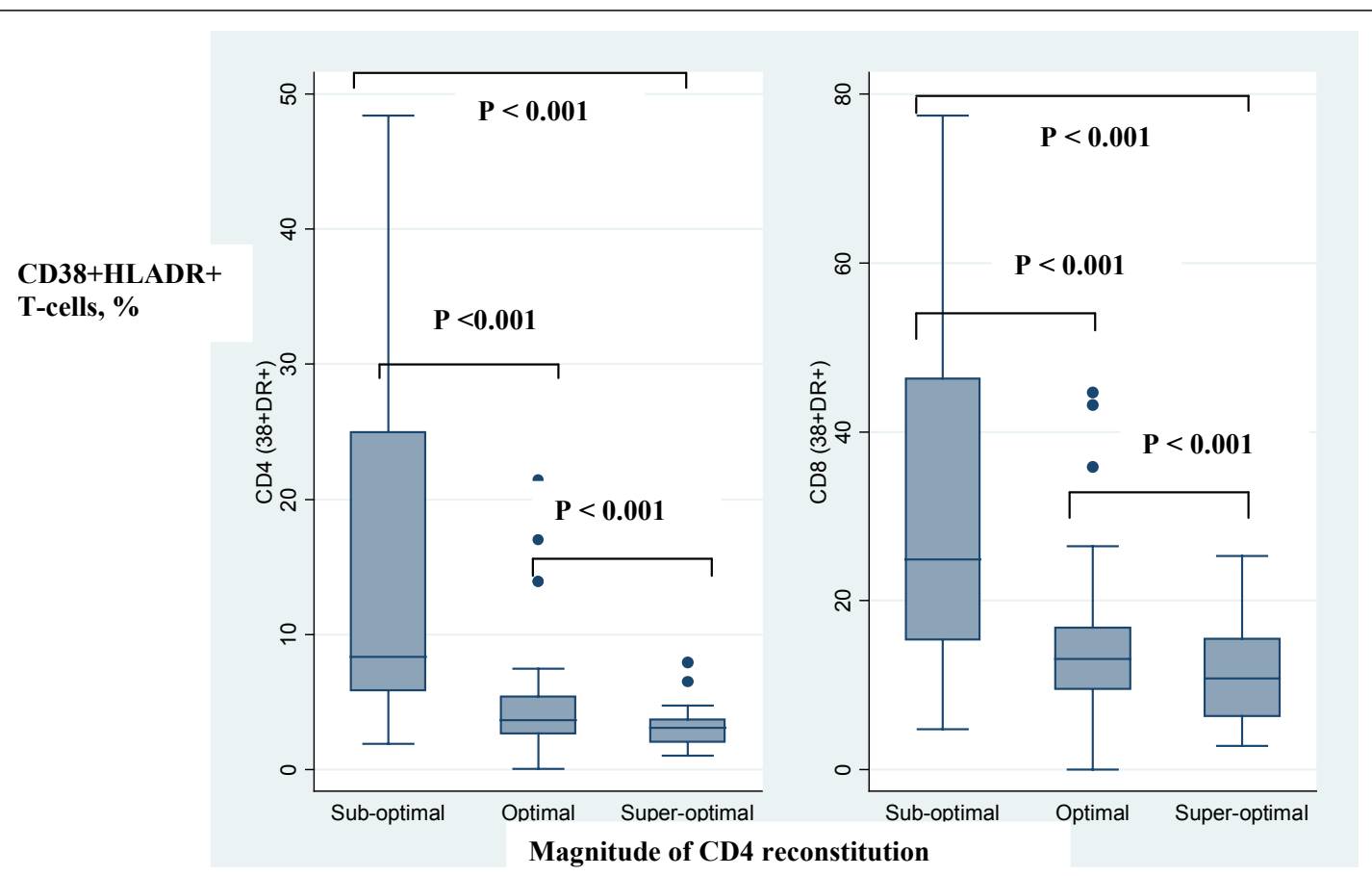

Figure 3 T-cell activation and magnitude of CD4 count increase among HIV-infected patients after 4 years of antiretroviral therapy and sustained HIV-RNA viral suppression. Immune activation, was measured by co-expression of HLADR and CD38 (CD38+HLADR+). The percentages of activated CD4 (CD438+HLADR+) and CD8 (CD8 CD38+ HLADR+) T-cells were plotted against CD4 count reconstitution. Immune activation of CD4 and CD8 T-cells was higher among patients with suboptimal CD4 reconstitution (patients that lie in the lowest quartile of CD4 increase) relative to the super-optimal responders (patients that lie in the highest quartile of CD4 increase) $\mathrm{P}=0.001$. The boxes span the $25^{\text {th }}$ and $75^{\text {th }}$ percentile values, the error bars span the $10^{\text {th }}$ and $90^{\text {th }}$ percentile values, and the dots represent individual observations above the $90^{\text {th }}$ percentile values.

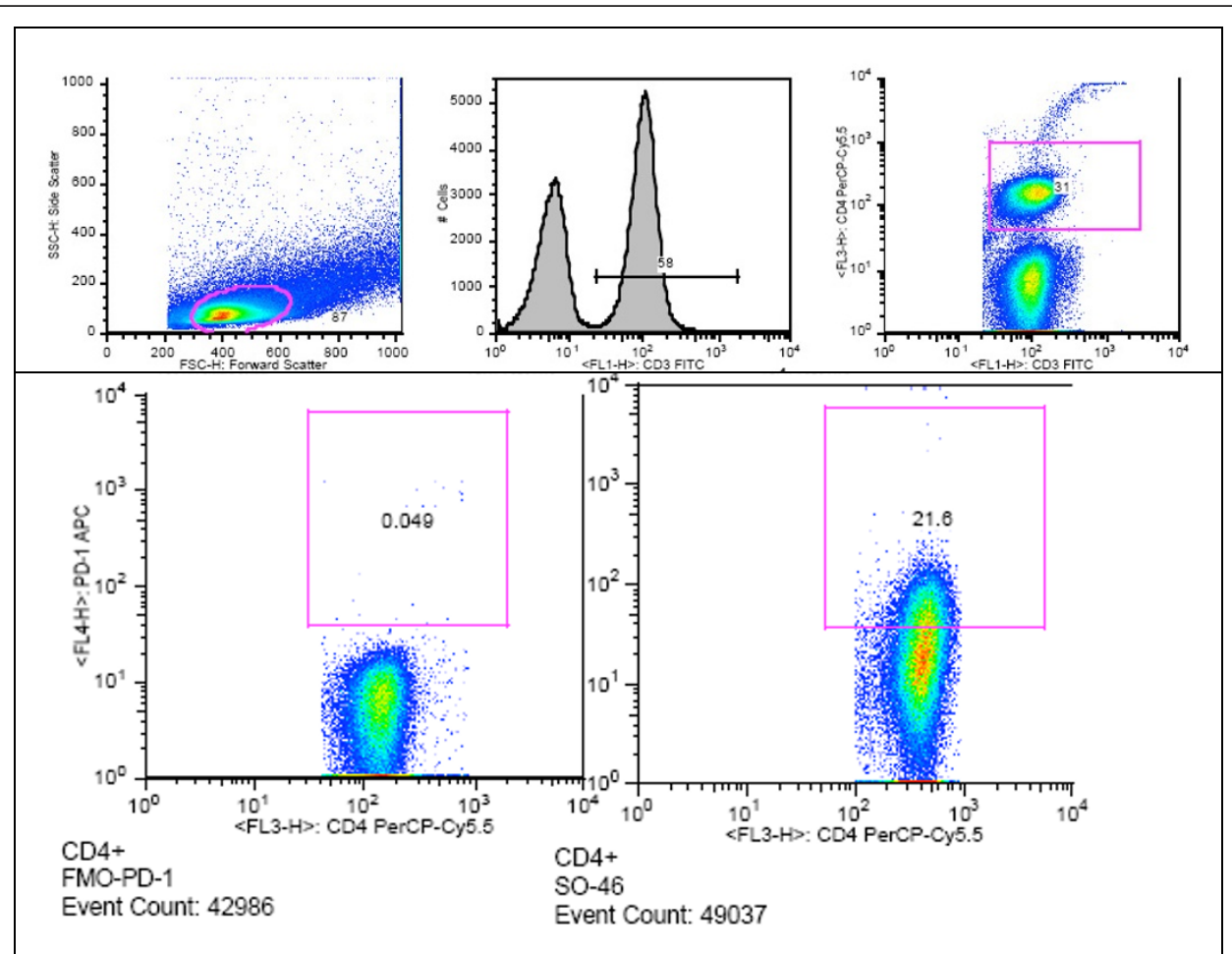

Figure 4 Flow cytometry analysis of PD1+ CD4 T cells for an individual with suboptimal CD4 reconstitution. The upper panel shows the gating strategy for the PD1+ T cells that are marked for apoptosis. The lower panel shows the fluorescence minus one control (FMO) for PD1 (left) and a typically high proportion of PD1+ cells (right). 


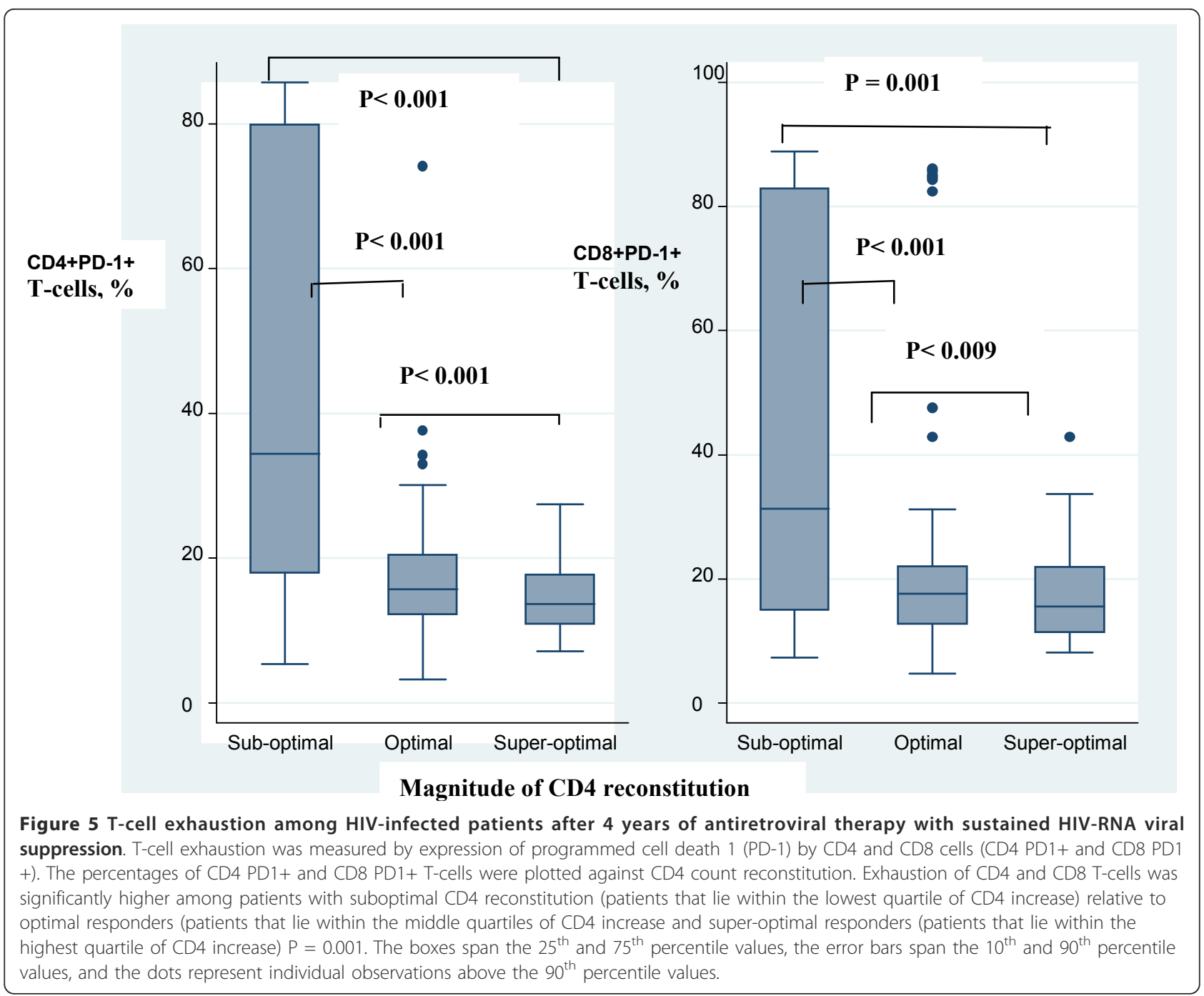

Table 2 T-cell immune activation, cell exhaustion and peripheral blood parameters among patients with and without suboptimal CD4 reconstitution after 4 years of antiretroviral therapy

\begin{tabular}{|c|c|c|c|c|c|}
\hline Parameters measured after 4 years of ART & $\begin{array}{l}\text { Suboptimal CD4 } \\
\text { reconstitution } \\
\text { (Cases) } \mathrm{N}=34\end{array}$ & $\begin{array}{l}\text { Super-Optimal CD4 } \\
\text { reconstitution } \\
\text { (Controls) } \mathrm{N}=30\end{array}$ & P-value * & $\begin{array}{l}\text { Adjusted OR } \\
(95 \% \mathrm{Cl})\end{array}$ & P-value \\
\hline \multicolumn{6}{|l|}{ Immune activation } \\
\hline CD4 HLADR+ CD38+ [Median (IQR)] & $7.9(4.9-16.4)$ & $2.8(2.0-3.6)$ & $<0.001$ & $5.7(1.4-23.0)$ & 0.014 \\
\hline CD8 HLADR+ CD38+ [Median (IQR)] & $22.5(15.3-44.9)$ & $10.396 .3-15.1)$ & $<0.001$ & $0.8(0.6-1.1)$ & 0.107 \\
\hline \multicolumn{6}{|l|}{ Cell exhaustion } \\
\hline CD4 PD1+ [Median (IQR)] & $34.3(17.6-78.8)$ & $7.3(4.7-9.4)$ & $<0.001$ & $1.5(1.1-2.1)$ & 0.022 \\
\hline CD8 PD1+ [Median (IQR)] & $30.6(13.4-82.9)$ & $7.9(6.2-9.5)$ & $<0.001$ & $1.2(0.9-1.5)$ & 0.130 \\
\hline \multicolumn{6}{|l|}{ Peripheral blood parameters } \\
\hline Hemoglobin (mg/dl) [Median (IQR)] & $13(12-14)$ & $14(12-15)$ & 0.293 & & \\
\hline MCV (fl) [Median (IQR)] & $102(96-112)$ & $109(98-112)$ & 0.264 & & \\
\hline $\begin{array}{l}\text { Total white blood cell count } \\
\text { [Median (IQR)] }\end{array}$ & $3530(3000-4050)$ & $5050(4240-5720)$ & 0.003 & & \\
\hline Lymphocytes \% [Median (IQR)] & $37(30-46)$ & $45(36-51)$ & 0.278 & & \\
\hline Neutrophils \% [Median (IQR)] & $45(40-59)$ & $42(38-50)$ & 0.820 & & \\
\hline Eosinophils \% [Median (IQR)] & $4(1-8)$ & $2(1-3)$ & 0.012 & & \\
\hline Platelet count $n \times 10^{3}$ [Median (IQR)] & $235(205-284)$ & $292(214-318)$ & 0.359 & & \\
\hline
\end{tabular}

*Wilcoxon rank-sum test, $¥$ Chi square, MCV, mean corpuscular volume. 
and possibly improves T-cell function recovery. Therefore early targeted and aggressive intervention in the population with suboptimal immune recovery may be beneficial [28-30].

The high levels of $\mathrm{T}$-cell immune-activation did not correlate with the presence of co-infections including tuberculosis, cryptococcal meningitis, Pneumocystis iiroveci pneumonia, toxoplasmosis, oro-esophageal candidiasis and malaria. This result is consistent with our previous report that AIDS-related events were no more among patients with and without suboptimal CD4 reconstitution [6]. Similarly, none of the patients was found to have intestinal helminthiasis despite living in a region where the infection is endemic. The authors attribute this to the fact that this was a selected population that receives comprehensive screening, treatment and prevention of co-infections that includes among others; cotrimoxazole prophylaxis, regular de-worming and a safe water vessel; all of which reduce the risk of the co-infections [31-34].

Expression of programmed cell death 1 (PD-1) was significantly up-regulated on T-cells of suboptimal responders relative to super-optimal responders. Significant difference in T-cell immune activation and exhaustion was observed despite undetectable viremia. This implies that ongoing viral replication may not be the driver of PD-1 expression as previously reported [35]. However, our results are in agreement with evidence that increased apoptosis and intrinsic $\mathrm{T}$-cell death play a role in incomplete CD4 count recovery [7]. There is need for further studies to determine other potential drivers of both immune activation and PD-1 expression among HIV-infected patients on successful ART. Similarly, advances to regulate these immunological abnormalities may modify CD4 count recovery among ARTtreated HIV-infected patients with suboptimal CD4 reconstitution.

Our study design did not permit determination of the causation of immune dysregulation. Although majority of available data suggests that immune activation is most likely a cause of the damaged immune system rather than a consequence [30], it is possible that lack of CD4 recovery could be the cause and not a consequence of the immune impairment [36]. We did not compare levels of immune activation among patients with and without viral suppression however there is already evidence that ART decreases immune activation levels over time [1,37].

\section{Conclusion}

T-cell activation and exhaustion persist among HIVinfected patients despite long-term, sustained HIV-RNA viral suppression. These immune abnormalities were associated with suboptimal CD4 reconstitution and their regulation may modify immune recovery among ARTtreated patients with suboptimal CD4 reconstitution despite sustained viral suppression.

\section{Acknowledgements}

The authors thank the staff of the Adult infectious Disease Clinic research cohort for supporting the data collection, the CTL laboratory at the Joint Clinic Research Center were we performed the laboratory assays and the patients for accepting to participate in this study. The work was supported by the Gilead-funded Sewankambo clinical research scholarship program at the Infectious Diseases Institute, Makerere University College of Health Sciences.

\section{Author details}

${ }^{1}$ Department of Medicine, Makerere University School of Medicine, Kampala, Uganda. ${ }^{2}$ Infectious Diseases Institute, Makerere University School of

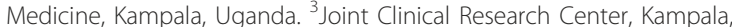
Uganda. ${ }^{4}$ California Department of Public Health, Richmond, California 94804 USA. ${ }^{5}$ Institute of Tropical Medicine, Department of Clinical sciences, HIV/STD Unit, Antwerp, Belgium. ${ }^{6}$ Department of Epidemiology and Social Sciences, University of Antwerp, Antwerp, Belgium.

\section{Authors' contributions}

DN made substantial contribution to the conception, design, data collection, analysis and drafting of the manuscript. IS contributed to the immune assays, data analysis and interpretation. HMK contributed to the conception, design, data interpretation and revision of the manuscript. AK made substantial contribution to the study design and the statistical analysis. RC and YCM contributed to the conception, data interpretation and revision of the manuscript. RN contributed to the data collection and MRK contributed to the conception, design, data interpretation and revision of the manuscript. HC made substantial contribution to the conception, design, immune assays, data analysis, interpretation and revision of the manuscript. All authors read and approved the final manuscript.

\section{Competing interests}

The authors declare that they have no competing interests.

Received: 9 September 2010 Accepted: 8 February 2011 Published: 8 February 2011

\section{References}

1. Benito JM, Lopez M, Martin JC, Lozano S, Martinez P, Gonzalez-Lahoz J, Soriano V: Differences in cellular activation and apoptosis in HIV-infected patients receiving protease inhibitors or nonnucleoside reverse transcriptase inhibitors. AIDS Res Hum Retroviruses 2002, 18(18):1379-1388.

2. Hunt PW, Brenchley J, Sinclair E, McCune JM, Roland M, Page-Shafer K, Hsue P, Emu B, Krone M, Lampiris $H$, et al: Relationship between T cell activation and CD4+ T cell count in HIV-seropositive individuals with undetectable plasma HIV RNA levels in the absence of therapy. $J$ Infect Dis 2008, 197(1):126-133.

3. Massanella M, Negredo E, Perez-Alvarez N, Puig J, Ruiz-Hernandez R, Bofill M, Clotet B, Blanco J: CD4 T-cell hyperactivation and susceptibility to cell death determine poor CD4 T-cell recovery during suppressive HAART. AIDS 2010, 24(7):959-968.

4. Almeida CA, Price $P$, French MA: Immune activation in patients infected with HIV type 1 and maintaining suppression of viral replication by highly active antiretroviral therapy. AIDS Res Hum Retroviruses 2002, 18(18):1351-1355.

5. Kelley CF, Kitchen CM, Hunt PW, Rodriguez B, Hecht FM, Kitahata M, Crane HM, Willig J, Mugavero M, Saag M, et al: Incomplete peripheral CD4 + cell count restoration in HIV-infected patients receiving long-term antiretroviral treatment. Clin Infect Dis 2009, 48(6):787-794.

6. Nakanjako D, Kiragga A, Ibrahim F, Castelnuovo B, Kamya MR, Easterbrook PJ: Sub-optimal CD4 reconstitution despite viral suppression in an urban cohort on antiretroviral therapy (ART) in sub-Saharan Africa: frequency and clinical significance. AIDS Res Ther 2008, 5:23.

7. Negredo E, Massanella M, Puig J, Perez-Alvarez N, Gallego-Escuredo JM, Villarroya J, Villarroya F, Molto J, Santos JR, Clotet B, et al: Nadir CD4 T cel 
count as predictor and high CD4 T cell intrinsic apoptosis as final mechanism of poor CD4 T cell recovery in virologically suppressed HIVinfected patients: clinical implications. Clin Infect Dis 2010, 50(9):1300-1308.

8. Wilson CM, Ellenberg JH, Douglas SD, Moscicki AB, Holland CA: CD8+CD38 + T cells but not HIV type 1 RNA viral load predict CD4+ T cell loss in a predominantly minority female HIV+ adolescent population. AIDS Res Hum Retroviruses 2004, 20(3):263-269.

9. Benito JM, Lopez M, Lozano S, Ballesteros C, Capa L, Martinez P, GonzalezLahoz J, Soriano V: CD4+ T cell recovery beyond the first year of complete suppression of viral replication during highly active antiretroviral therapy is not influenced by CD8+ T cell activation. $J$ Infect Dis 2005, 192(12):2142-2146.

10. Hunt PW, Martin JN, Sinclair E, Bredt B, Hagos E, Lampiris H, Deeks SG: T cell activation is associated with lower CD4+ T cell gains in human immunodeficiency virus-infected patients with sustained viral suppression during antiretroviral therapy. J Infect Dis 2003, 187(10):1534-1543.

11. Baker CA, Emenyonu N, Ssewanyana I, Jones NG, Elrefaei M, Nghania F, Nakiwala J, Andia I, Clark R, Martin J, et al: Profile of immunologic recovery in HIV-infected Ugandan adults after antiretroviral therapy. AIDS Res Hum Retroviruses 2007, 23(7):900-905.

12. Cassol E, Malfeld S, Mahasha P, van der Merwe S, Cassol S, Seebregts C, Alfano M, Poli G, Rossouw T: Persistent microbial translocation and immune activation in HIV-1-infected South Africans receiving combination antiretroviral therapy. J Infect Dis 2010, 202(5):723-733.

13. Borkow G, Weisman Z, Leng Q, Stein M, Kalinkovich A, Wolday D, Bentwich Z: Helminths, human immunodeficiency virus and tuberculosis. Scand J Infect Dis 2001, 33(8):568-571.

14. Rosignoli G, Lim CH, Bower M, Gotch F, Imami N: Programmed death (PD)1 molecule and its ligand PD-L1 distribution among memory CD4 and CD8 $T$ cell subsets in human immunodeficiency virus-1-infected individuals. Clin Exp Immunol 2009, 157(1):90-97.

15. Rosignoli G, Cranage A, Burton C, Nelson M, Steel A, Gazzard B, Gotch F, Imami N: Expression of PD-L1, a marker of disease status, is not reduced by HAART in aviraemic patients. AIDS 2007, 21(10):1379-1381.

16. Venkatachari NJ, Buchanan WG, Ayyavoo V: Human immunodeficiency virus (HIV-1) infection selectively downregulates PD-1 expression in infected cells and protects the cells from early apoptosis in vitro and in vivo. Virology 2008, 376(1):140-153.

17. Kamya MR, Mayanja-Kizza H, Kambugu A, Bakeera-Kitaka S, Semitala F, Mwebaze-Songa P, Castelnuovo B, Schaefer P, Spacek LA, Gasasira AF, et al: Predictors of long-term viral failure among ugandan children and adults treated with antiretroviral therapy. J Acquir Immune Defic Syndr 2007, 46(2):187-193.

18. Teixeira L, Valdez H, McCune JM, Koup RA, Badley AD, Hellerstein MK, Napolitano LA, Douek DC, Mbisa G, Deeks S, et al: Poor CD4 T cell restoration after suppression of HIV-1 replication may reflect lower thymic function. AIDS 2001, 15(14):1749-1756.

19. Kaufmann GR, Furrer $H$, Ledergerber B, Perrin L, Opravil M, Vernazza P, Cavassini M, Bernasconi E, Rickenbach M, Hirschel B, et al: Characteristics, determinants, and clinical relevance of CD4 T cell recovery to $<500$ cells/microL in HIV type 1-infected individuals receiving potent antiretroviral therapy. Clin Infect Dis 2005, 41(3):361-372.

20. Giovannetti A, Ensoli F, Mazzetta F, De Cristofaro M, Pierdominici M, Muratori DS, Fiorelli V, Aiuti F: CCR5 and CXCR4 chemokine receptor expression and beta-chemokine production during early $\mathrm{T}$ cell repopulation induced by highly active anti-retroviral therapy. Clin Exp Immunol 1999, 118(1):87-94.

21. Bouscarat F, Levacher M, Landman R, Muffat-Joly M, Girard PM, Saimot AG, Brun-Vezinet F, Sinet M: Changes in blood CD8+ lymphocyte activation status and plasma HIV RNA levels during antiretroviral therapy. AIDS 1998, 12(11):1267-1273.

22. Valdez H: Immune restoration after treatment of HIV-1 infection with highly active antiretroviral therapy (HAART). AIDS Rev 2002, 4(3):157-164.

23. De Maria A: Discordant responses to HAART in HIV-1 patients: the need to focus on intervention. Expert Rev Anti Infect Ther 2007, 5(4):523-527.

24. Watson C, Jenkinson S, Kazmierski W, Kenakin T: The CCR5 receptor-based mechanism of action of 873140 , a potent allosteric noncompetitive HIV entry inhibitor. Mol Pharmacol 2005, 67(4):1268-1282.
25. Mwagomba B, Zachariah R, Massaquoi M, Misindi D, Manzi M, Mandere BC, Bemelmans M, Philips M, Kamoto K, Schouten EJ, et al: Mortality reduction associated with HIV/AIDS care and antiretroviral treatment in rural Malawi: evidence from registers, coffin sales and funerals. PLoS One 2010, 5(5):e10452.

26. Walensky RP, Wood R, Weinstein MC, Martinson NA, Losina E, Fofana MO, Goldie SJ, Divi N, Yazdanpanah Y, Wang B, et al: Scaling up antiretroviral therapy in South Africa: the impact of speed on survival. J Infect Dis 2008, 197(9):1324-1332.

27. Lawn SD, Little F, Bekker LG, Kaplan R, Campbel E, Orrell C, Wood R: Changing mortality risk associated with $\mathrm{CD} 4$ cell response to antiretroviral therapy in South Africa. Aids 2009, 23(3):335-342.

28. Bandera A, Ferrario G, Saresella M, Marventano I, Soria A, Zanini F, Sabbatini F, Airoldi M, Marchetti G, Franzetti F, et al: CD4+ T cell depletion, immune activation and increased production of regulatory $T$ cells in the thymus of HIV-infected individuals. PLoS One 2010, 5(5):e10788.

29. Gazzola L, Tincati C, Bellistri GM, Monforte A, Marchetti G: The absence of CD4+ T cell count recovery despite receipt of virologically suppressive highly active antiretroviral therapy: clinical risk, immunological gaps, and therapeutic options. Clin Infect Dis 2009, 48(3):328-337.

30. Sondora LD, Silvestri G: Immune activation and AIDS pathogenesis. 2008 [http://www.medscape.com/viewarticle/575812].

31. Lule JR, Mermin J, Ekwaru JP, Malamba S, Downing R, Ransom R, Nakanjako D, Wafula W, Hughes P, Bunnell R, et al: Effect of home-based water chlorination and safe storage on diarrhea among persons with human immunodeficiency virus in Uganda. Am J Trop Med Hyg 2005, 73(5):926-933.

32. Mermin J, Ekwaru JP, Liechty CA, Were W, Downing R, Ransom R, Weidle P, Lule J, Coutinho A, Solberg P: Effect of co-trimoxazole prophylaxis, antiretroviral therapy, and insecticide-treated bednets on the frequency of malaria in HIV-1-infected adults in Uganda: a prospective cohort study. Lancet 2006, 367(9518):1256-1261.

33. Mermin J, Lule JR, Ekwaru JP: Association between malaria and CD4 cell count decline among persons with HIV. J Acquir Immune Defic Syndr 2006, 41(1):129-130.

34. Watera C, Todd J, Muwonge R, Whitworth J, Nakiyingi-Miiro J, Brink A, Miiro G, Antvelink L, Kamali A, French N, et al: Feasibility and effectiveness of cotrimoxazole prophylaxis for HIV-1-infected adults attending an HIV/ AIDS clinic in Uganda. J Acquir Immune Defic Syndr 2006, 42(3):373-378.

35. D'Souza M, Fontenot AP, Mack DG, Lozupone C, Dillon S, Meditz A, Wilson CC, Connick E, Palmer BE: Programmed death 1 expression on HIV-specific CD4+ T cells is driven by viral replication and associated with T cell dysfunction. J Immunol 2007, 179(3):1979-1987.

36. Piconi S, Trabattoni D, Gori A, Parisotto S, Magni C, Meraviglia P, Bandera A, Capetti A, Rizzardini G, Clerici M: Immune activation, apoptosis, and Treg activity are associated with persistently reduced CD4+ T-cell counts during antiretroviral therapy. AIDS 2010, 24(13):1991-2000.

37. Ssewanyana I, Baker CA, Ruel T, Bousheri S, Kamya M, Dorsey G, Rosenthal PJ, Charlebois E, Havlir D, Cao H: The Distribution and Immune Profile of T Cell Subsets in HIV-Infected Children from Uganda. AIDS Res Hum Retroviruses 2009, 25(1):65-71.

\section{Pre-publication history}

The pre-publication history for this paper can be accessed here: http://www.biomedcentral.com/1471-2334/11/43/prepub

doi:10.1186/1471-2334-11-43

Cite this article as: Nakanjako et al:: High T-cell immune activation and immune exhaustion among individuals with suboptimal CD4 recovery after 4 years of antiretroviral therapy in an African cohort. BMC Infectious Diseases 2011 11:43. 